\title{
Centenário de nascimento de Cândido Nazianzeno Nogueira da Motta.
}

\author{
Em sessão comemorativa do centenário de nascimento \\ de Cândido Nazianzeno Nogueira da Motta, rezniu-se a \\ Congregação de professôres desta Faculdade, no salão \\ nobre, aos 15 de maio do corrente ano. \\ Na presidência da mesa, o Prof. Migucel Reale, magni- \\ fico reitor da Universidade de São Paulo, deu a palavra co \\ emérito professor Noé Azevedo, que em esplêndida oração \\ fêz o laudatório do homenageado.
}

Oração do professor emérito Noé Azevedo.

Cândido Motta é descendente de uma família de intelectuais. Seu pai Fernando Motta era professor e diretor de colégio na cidade de $N$. S. do Amparo. Sua mãe, Mariana Motta, era poetiza, escrevia nos jornais de Capivarí e Pôrto Feliz.

No livro de Carneiro Leão sôbre Victor Hugo no Brasil há um comentário sôbre o fato de Mariana morando numa cidadezinha à margem do Tietê, haver chorado, emocionadíssima com a morte de Victor Hugo!

Quando Cândido Motta saíu de Porto Feliz para São Paulo foi para fazer seus primeiros exames no curso anexo, na Faculdade de Direito onde foi companheiro e colega de classe de Reynaldo Porchat e Gabriel de Rezende, assistiu e participou do movimento pela República compenetrado disso. aincla mais porque seu pai e seu avô estiveram em Itú em 1870. 
Formado, foi Promotor Público no Amparo, Delegado de Polícia e Promotor nesta Capital. Em 1897 fêz concurso para a Faculdade com a tese sôbre a Classificação de criminosos.

Participou intensamente da vida política tendo sido vereador, deputado estadual e senador estadual. Fêz parte da dissidência com Júlio de Mesquita e com êste dirigiu o jornal "O tempo". Como deputado pleiteou pela reforma do juri; defendeu a autonomia municipal, e ofereceu o primeiro projeto, no país, de Instituto Educativo para Menores abandonados.

Na Câmara Federal foi relator do Código Penal Militar.

Por indicação de Herculano de Freitas foi representante do Brasil no Congresso Pan Americano, em Santiago do Chile onde foi aprovada a sua tese sôbre menores delinqüentes e seu tratamento.

Fêz a campanha civilista ao lado de Rui Barbosa e esteve sempre ao seu lado, mesmo quando o Partido Republicano mudou de orientação.

Participou do govêrno Altino Arantes como Secretário da Agricultura, Comércio e Obras Públicas. Criou o ensino primário circulante para a zona agrária e presidiu o primeiro Congresso de Estradas de Rodagem sob o lema "Via Vita".

Encerrou sua atividade política como senador estadual.

Sua produção cultural não se limitou ao campo do Direito, mas se distendeu para o campo da teoria política, da História e da sociologia criminal.

Escreveu sôbre Anchieta, sôbre São Paulo na República, sôbre As antigas penalidades. O crime politico, A mâo de obra penal, sôbre o Problema semita e finalmente Agora e sempre pela República e pelo Parlamentarismo.

Uma de suas preocupações na velhice, foi o da conservação do "Pôrto das Monções" em Pôrto Feliz que conseguira restaurar com as barcaças bandeirantes. 
Eis em resumo os atos principais de uma longa vida intensa e proficuamente vivida.

Impossibilitado de apresentar ao menos um esquema dos numerosos assuntos de direito penal desenvolvidos em longas dissertações pelo Prof. CÂndiDo MoTta, em dezenas de monografias publicadas em volumes ou insertas na Revista da Faculdade de Direito, farei apenas algumas anotações, tendentes a mostrar a decisiva influência que êle exerceu na transformação de nossos institutos penais, defendendo com grande coragem e intenso vigor os principios da Escola Positiva.

$\mathrm{Na}$ ocasião em que fêz concurso, ainda dominavam nesta Casa as concepções metafísicas do direito, apesar do intenso trabalho de arejamento iniciado pelo grande Pedro LEssa. Constituíu, portanto, uma verdadeira ousadia a apresentação de um estudo vasado no estilo revolucionário de Ferri, Lombroso, Garofalo e demais companheiros do positivismo. Com desassombro, compareceu Cândido Motta perante a Congregação, em 1897, com a sua Classificação dos Criminosos, em cuja introdução formulou as seguintes posições :

"O fim principal da pena é a defêsa da sociedade, principio êste que é reconhecido pela grande maioria de criminalistas, desde Beccaria ao mais ferrenho de todos os clássicos, o mais metafísico dêles, o célebre $F$. Carrara.

"Admitido êsse princípio, fàcilmente se chega à conclusão do quanto de errôneo tem o critério com que os legisladores têm encarado o problema de repressão.

" $E$, de fato, quer se considere o delito como uma mera perturbação da ordem jurídica, pela violação daquilo que a lei convencional e escrita proíbe de o fazer, quer como um fenômeno natural e necessário, pela violação dos sentimentos fundamentais de piedade e probidade, cujo conjunto forma o senso moral, vemos, com a observação e experiência de todos os dias, que não é o crime que devemos combater, porque a despeito de todo esfôrço 
possivel e imaginável, êle subsistirá com êsse caráter de fatalidade que caracteriza principalmente o mundo físico.

"O crime é um fato abstrato; para seu agente, o homem que o pratica, é que devem convergir as vistas da sociedade colocada em atitude de legítima defesa.

"O fenômeno criminal varia de indivíduo a indivíduo, com as moléstias."

Como todos os pregadores de idéias novas, ao lado de princípios verdadeiros e dominadores como êsses, defendeu pontos de vista menos seguros e avançou pelos exagêros naîurais. Pôs as suas observações no serviço policial do Estado ao lado das de Lombroso e outros pesquisadores dos caracteres somáticos do homem criminoso típico. Essas diligências não puderam. todavia, passar das áreas do empirismo. Se eram freqüentes as malformações físicas e os estígmas de degenerescência nos criminosos, não foi possivel, entretanto determinar-se uma relação constante entre os mesmos e a criminalidade. Nem se conseguiu ligar as várias formas de criminalidade aos vários tipos antropológicos.

O problema recebe hoje nova e intensa luz, projetada pelos estudos da endocrinologia e biotipologia. Procura-se agora estabelecer relação entre as malformações físicas e o mau funcionamento de determinadas glândulas de secreção interna. Quando os distúrbios glandulares, além de provocarem a feiura, também atuam sôbre a constituição psicológica, produzindo temperamentos impulsivos, abúlicos ou viscosos, podem surgir daí vários tipos de criminosos.

Já os antigos fisionomistas, precursores das especulações lombrosianas, procuravam estabelecer certa relação entre os instintos maus e a feiura. E Sócrates, quando condenado pela mais iníqüa das sentenças, pois representa na História êsse filosofo a personificação da bondade, disse aos seus discipulos que um dêsses fisionomistas, impressionado com a sua fealdade, fizera um prognóstico desfavorável sôbre a sua conduta no mundo, pelo que passara a 
recalcar todos os pendores maus e a dirigir os seus atos de acôrdo com os ensinamentos da moral que pregou.

Agora, temos, em nossa Penitenciária do Estado, um serviço científico de biotipologia, empenhado em formular prognósticos criminológicos sôbre a readaptação ou a reincidência dos sentenciados que pleiteiam comutação ou livramento condicional.

O próprio Nicola Pende, criador da nova ciência, entende que ela se destina a iluminar um largo setor do problema da constituição física e psíquica dos indivíduos. mas que está muito longe de proporcionar regras para conclusões verdadeiramente científicas.

Verifica-se, porém, que não foi improfícuo o trabalho da Escola Positiva, mesmo naquela vereda lombrosiana "dell'uomo delinquente". Aquêles outros postulados que recomendavam deixar em segundo plano o crime ou fato criminoso, para ter-se na maior atenção a pessoa do delinqüente, foram se impondo à consciência de todos os penalistas e pode-se dizer que dominaram decisivamente a ciência penal, achando-se consubstanciados em disposições concretas de todos os Códigos modernos e de todos os projetos ainda em estudos.

No alentado volume Scritti in onore de Enrico Ferri, publicado em 1929, por ocasião de seu jubileu científico. encontra-se um balanço das duas escolas penais, feito por ENRico DE Nicola. Examina êle todos os institutos que vão sendo introduzidos na legislação nova, em virtude da doutrinação positivista, desde o "sursis" e o livramento condicional até as medidas de segurança.

Mostra que as inovações eram tão numerosas que Silvio LoNGHI chegara a propor que se elaborassem dois códigos, um contendo disposições repressivas, seguindo preponderantemente os ensinamentos da Escola Clássica, e um outro consubstanciando as disposições preventivas propugnadas pela Escola Positiva. Mas o que afinal veio a prevalecer, 
em todos os projetos e nos Códigos que tem sido publicados nos últimos tempos inclusive no Código Italiano de 1930 e no Brasileiro de 1940, foi a harmonização das duas Escolas, tendo êsses monumentos legislativos acolhido a contribuição verdadeiramente impressionante da Escola Positiva, destinada à prevenção dos delitos e à individualização da pena.

E Cândido Motta tem, nessa estrondosa vitória do positivismo na legislação criminal brasileira, a mais confortante das recompensas, porque foi não sòmente um dos pioneiros do movimento no Brasil, como continuou sendo durante mais de 40 anos o combatente mais convicto. A sua atuação se realizou principalmente na Cátedra, criando. com o inolvidável Gama CerqueIra, a mentalidade positivista e pragmática da maioria dos cultores do direito penal no Brasil, formados por mais de seis turmas de estudantes que ouviram as suas sábias lições.

Estas aí estão, nas inúmeras edições mimeografadas e impressas, para atestar-lhe a limpidêz do pensamento; e, ao lado delas, os substanciosos artigos e opúsculos publicados durante 40 anos.

Dentre êstes, destaca-se a Memória sôbre os menores delinqüentes e seu tratamento no Estado de São Paulo, apresentada ao $1^{\circ}$ Congresso Científico Pan-Americano reunido em Santiago do Chile em 1909.

Como deputado estadual, apresentou êle em 1900, à respectiva Câmara, o projeto de instalação nesta Capital do "Instituto Educativo Paulista." As idéias novas contidas no mesmo provocaram intenso debate no congresso legislativo, especialmente no Senado, onde sofreu emendas, aparentemente de pouca importância, mas que vieram a demonstrar mais tarde a inconveniência de se quebrar o sistema idealizado por um técnico, que vira o problema no seu conjunto e em tôdas as suas minúcias. A própria mudança do nome, que passou a ser o de Instituto Disci- 
plinar, constituíu um grande êrro, pois as idéias de pena e disciplina andam intimamente ligadas. Com muito mais simpatia seria o estabelecimento encarado se o seu nome sugerisse a idéia de uma casa de ensino, e não de um presídio.

Mas a emenda mais funesta foi a que, sob pretexto de não admitir o Código Penal da República o regime celular para menores, fêz uma nova divisão de classes, seguindo mais ou menos o critério das idades, em vez de adotar o da perversão ou corrigibilidade, que norteara o projeto.

Assim, não foi possivel fazer-se um estudo individualizado de cada um dos menores recolhidos ao estabelecimento, a fim de proceder-se posteriormente à classificação, de maneira a evitar que os já pervertidos viessem a corromper os bons e que os delinqüentes ficassem em contacto com os simplesmente abandonados.

A página 91 da referida memória, consignou Cândido Motta estas ponderações, a respeito da emenda:

"Outro ponto de nosso projeto que provocou os mais vivos protestos foi o que dizia respeito ao regime celular.

"Ninguém então se apercebeu que a cela só era contemplada no projeto em obediência a determinação expressa do Código Penal. Chegou-se mesmo a afirmar no Senado que o projeto instituia a prisão celular, quando o Código Penal da República, vedava tal regime aos menores! Foi evidentemente um lápso que o próprio Senador Paulo Egydio deixou passar em silêncio.

"Se o instituto fôsse destinado exclusivamente aos maiores de nove anos e menores de 14, que obrassem com discernimento ou aos menores vadios e vagabundos, as censuras seriam procedentes.

“Aos Estados da Federação Brasileira não é lícito legislar sôbre o direito penal; e para os menores da primeira categoria vigora a regra do artigo 30 do Código Penal, em virtude do qual serão êles recolhidos a estabele- 
cimentos disciplinares industriais, pelo tempo que ao juiz parecer, contanto que o recolhimento não exceda à idade de 17 anos e para os da segunda vigora o $\S 2 .^{\circ}$ do art. 399 , que os manda recolher a estabelecimentos disciplinares indistriais, onde poderão ser conservados até a idade de 21 anos.

"Sem embargo de tudo isso, resta ainda saber se um regime celular não pode ser acomodado dentro dos institutos disciplinares, já que o Código não preestabeleceu o regime dêstes; e se não será mesmo uma condição salutar para a boa disciplina."

Cita opiniões de Mercherz, Peyron, Puibaraud, Arboudx, Mme. Dupuybessiére e outros, escritores, diretores de escolas correcionais e de prisões na França favoráveis ao recolhimento dos menores durante certo período em celas ou compartimentos individuais, a fim de serem observados e posteriormente distribuídos pelas diferentes secções do estabelecimento. E acrescenta:

"Além de tudo, há celas e celas. As celas nos velhos estabelecimentos europeus, como nos nossos, são, na sua generalidade, uns cubículos imundos de onde os encarcerados jamais saem em perfeita saúde. Estas celas parecem até servir para sofismar a pena de morte, porque produzem igualmente a morte, mas disfarçada, lenta, que vai pouco a pouco roubando as energias do indivíduo, fazendo com que o seu organismo fique saturado de germes morbíficos que. mais cêdo ou mais tarde, determinam o seu completo aniquilamento para os misteres da vida."

Transcreve uma descrição impressionante de uma dessas prisões, feita por Enrico Ferri. E continua:

"As celas, porém, destinadas aos menores não podem ser tais cobicoli, que tanto horror causam aos homens de ciência: são quartos completamente isolados, segundo o nosso projeto, mas com a dimensão de três metros em quadra por quatro de altura. Numa cela destas o menor 
acha-se num bom aposento, com a cubagem de ar necessaria, com todo o confôrto, e portanto não pode dali sair enervado, o seu físico nada sofrerá e muito menos o seu moral; ao contrário, pode ter a calma e a energia para refletir sôbre as suas faltas e procurar o meio de corrigirse. afim de tornar-se útil a sí, aos seus e à sociedade."

Depois do advento da nova legislação sôbre menores abandonados e delinqüentes no Brasil, iniciada com a lei federal n. ${ }^{\circ} 4.242$ de 1921, o Estado de São Paulo criou o juízo especial de menores e deu as providências necessárias para a execução dessa lei. Nessa ocasião, em artigo publicado no "O Estado de São Paulo", tive ocasião de dizer que faltava, na organização feita de acôrdo com um projeto elaborado pelo Sr. Ministro Costa e Silva, uma peça que me parecia essencial, isto é, o Abrigo Provisório, com celas individuais para observação dos menores recolhidos, verdadeiro laboratório de triagem a fim de serem distribuidos os recolhidos pelos pavilhões competentes. Fêz-se mais tarde o abrigo, mas sem os aposentos individuais cue o velho professor e o novo doutrinador recomendavam. E o resultado é o que se tem visto: a indisciplina como base de tôda a vida no velho Instituto Disciplinar; a impossibilidade de evitar o contágio entre os delinqüentes e os simplesmente abandonados, entre os vadios e malandros inveterados e aquêles que para alí vão por não terem família. Não há diretor que consiga por ordem naquilo, nem mesmo os que para alí tem ido, e os que alí estão animados de verdadeira vocação apostolar.

Há em Londres um restaurante que fornece aos seus freguêses um cosido, cujo tempero já era elogiado por Dickens e que é sempre o mesmo há vários séculos, porque nunca se tira o fôgo e nem se esgota o fundo do caldeirão, que vai transmitindo o sabor primitivo aos novos ingredientes, diàriamente acrescentados. Assim é o famigerado Estabelecimento do bairro do Tatuapé: por não ter sido adotado o ponto de vista do grande técnico no assunto que 
era o Prof. Cândido Motta, formou-se ali um fermento de indisciplina, que vem se transmitindo de geração em geração dos seus freqüentadores, não havendo energias físicas nem morais capazes de endireitar aquilo, pois há sempre um núcleo de almas empedernidas capitaneando as manifestações de hostilidade, desarmando tôda a fôrça moral e vencendo até a paciência de Jesus, que alí já apareceu personificado no grande juiz de menores que foi Oliveira Cruz.

Nos eruditos discursos pronunciados em 1898, na Câmara dos Deputados (Revista da Faculdade de Direito, Ano de 1898, pgs. 194 à 297), desenvolveu CÂndido MotTa tôda a argumentação dos adeptos da Escola Positiva contra a instituição do juri. Foi eloqüente e mordaz. Não the parecia razoável que a ciência penal não conseguisse inventar um órgão judicante capaz de assentar a justiça das suas decisões em normas jurídicas rigorosas, de maneira que o seu acêrto se equiparasse ao das leis científicas. O "veredictum" dos leigos sôbre assunto de ordem técnica, como é o da aplicação do direito, parecia-lhe coisa tão aventurosa como tripular um barco com 12 individuos tirados à sorte, impelindo o mesmo para o alto mar, sem verificar prèviamente se algum dêles tinha conhecimentos, mesmo superficiais, da arte náutica.

Em 1924, ao discutir nova reforma do juri no Senado paulista, voltou à carga contra a instituição, que, numa sociedade civilizada, parecia-lhe aferrada a um método tão empírico de julgar, como o de tirar a sorte jogando os dados.

Mas, uma vez que se devia manter a instituição, entendia êle havia de conservar-se com os seus característicos essenciais. Profligou, porisso, com grande veemência, um dispositivo do projeto que estabelecia o julgamento secreto nos crimes sexuais.

Mostrou que não havia razão para temer o escândalo e que o decôro do Tribunal nada sofreria com a discussão 
em público de fatos escabrosos, sendo muito mais prejudicial a exploração que dos mesmos costumavam fazer a imprensa e o cinema antes da censura. Mostrou que desde o direito romano a publicidade dos debates constituía uma das garantias dos direitos do cidadão. E terminou com cstas palavras candentes de FERri, o grande chefe da Escola:

"Mas, enquanto essa abolição não for proposta nem sancionada pela lei, constitue irrefragável obrigação respeitar o instituto do juri, tal como a lei o assegura. E consideremos como sintoma de anarquia moral ferir êsse instituto a golpes de estilete, com decretos que, sob pretexto de coordenar o novo Código Penal com leis existentes, tiram ao juri a competência de cêrca de metade das causas que o Código de Processo lhe atribuia" (Revista da Faculdade. vol. 22, págs. 177 a 203).

No estudo sôbre As Antigas Penalidades (Revista citada. págs. 224 a 229), mostra-se o grande penitenciarista que tanto concorreu para transformar nos modernos estabelecimentos de ensino profissional e agricola, que hoje possuimos, os presídios brasileiros de então, que não passavam de depósito ou de colônias de sentenciados, atirados em salões infectos ou nas ilhas longinqüas, sempre na mais completa promiscuidade, como se vê da descricão que Souza Bandeira nos deixou da velha penitenciária imperial de Fernando Noronha.

No ensáio sôbre a mão de obra penal, que leu na Conferéncia de Criminologia reunida no Rio de Janeiro em 1933 (Revista da Faculdade. vol. 29, págs. 235 a 284), mais não faz do que reproduzir estudos antigos, como se vê da riquíssima bibliografia com que instrui os seus argumentos. Entretanto, as conclusões a que conduzia eram as mesmas rue vieram a ser consagradas modernamente, quer na reunião de 1926 da Associação Internacional de Direito Penal, quer no Congresso de Praga, sôbre as vantagens do trabalho al aperto. 
() seu pensamento é sempre o de que o trabalho higiênico constitui o melhor fator de regeneração. E nem podia conceber que ainda se viesse a discutir, no Congresso de Berlim de 1935, o postulado (que sempre the pareceu ao mesmo tempo jurídico, científico e humano) de que a finalidade principal da pena consiste em assegurar a defêsa da sociedade, propiciando ao mesmo tempo a readaptação do delinqüente ao meio social.

Na dissertação sôbre $O$ Crime Político (Revista da Faculdade de Direito, vol. 26, págs. 19 a 41), é onde melhor reponta uma das faces mais interessantes de seu espírito. Sendo positivista, estava, entretanto, muito longe da frieza com que os anatomistas da sociedade a dissecavam, não recuando diante de quaisquer conseqüências que daí adviessem, distribuindo, como Garofalo, penas eliminatórias com a mesma insensibilidade dos Torquemadas e Carpzovios. Estudando o crime político, encara a figura do idealista que se bate pela melhoria das instituições sociais, com verdadeira fé e sentimentos altruísticos. Sem ter citado Maxwell, que certamente ainda não havia publicado a sua distinção dos criminosos anterógrados e retrógrados quando o Prof. Cândido Motta assentara a sua doutrina sôbre o assunto, já estabelecia uma nítida distinção entre os espíritos geniais que precedem o seu tempo e agem impulsionados pelos grandes ideais, como Cristo e Sócrates, e as mentalidades primitivas, os intelectos primários, que são verdadeiras revivescências atávicas de homens de outras eras e que, a pretexto de revolução social, investem como bárbaros contra tôdas as instituições sociais.

$\mathrm{E}$ é ainda o mesmo espírito liberal que constitui o sedimento de tôdas as suas reflexões na esplêndida contribuição que escreveu para as festas anchietanas, sob o lema patriótico de São Paulo e a República. Amarra no fundo da história, nimbada de romantismo, da fundação de São Paulo as raízes da nacionalidade. Dá-lhe como tronco e 
sustentáculo o estupendo surto de ordem econômica, social e cultural que aquí se manifestou, aglutinando em tôrno de São Paulo as demais unidades da federação. É o justo orgulho do bom paulista e melhor brasileiro. que ai se expande.

E por fim vemos culminar tôda a espiritualidade do humanista no planfleto Nova Tormenta, êsse brado de revolta contra a pulverização de todos os princípios de moral, de direito e de justiça, que a religião havia inspirado e a ciência definira, em dois milênios de civilização. Cumpre, assim, o seu dever de intelectual.

Depois de Jules Benda haver chamado a atenção do mundo para La tranison des Clercs surge o líbelo de ArCHIbald Mac Leish, qual novo j'accuse, mostrando que são os intelectuais que devem responder por todo êsse descalabro que vai pelo mundo. Conservaram-se nas cômodas situações asseguradas pelo exercício das profissões liberais, do magistério da judicatura, das artes e das letras enquanto uma onda de anarquia e de ódio crescia entre as classes menos favorecidas da fortuna, dirigidas por falsos profetas, ia fazendo ruir o mundo desde os seus alicerces. Em outras quadras históricas tão tormentosas como a nossa e em que havia menos facilidade para a divulgação do pensamento e para transformar as idéias em fôrças sociais, correram para a liça os grandes tribunos, pregadores e escritores, tratando de dominar as expansões desordenadas, amainando o ódio, causticando as injustiças, levantando, acima das castas e das raças a bandeira da solidariedade humana.

CÂndido MotTa não traíu o seu dever. Consciente da sua responsabilidade intelectual, deixou o repouso a que tinha direito pela avançada idade e pela saúde cambalida, e veio a público com as suas duas últimas publicações, que constituem ao mesmo tempo uma advertência e um protesto. 
Advertência de que as nacionalidades tem de ser mantidas de acôrdo com a sua formação histórica, política e cultural.

Protesto - contra os semeadores do ódio, contra os pregadores da luta de raças, contra os novos messias que lançam o mundo nesta pavorosa confusão de Babel, que trovejam a guerra pelas ondas do ar, que revolvem a terra a dinamite, que fazem monstros de aço sacudir as águas do mar. E é o fôgo que cai do céu, completado pelo gênio infernal das torturas, aplicadas a sangue frio, degradando mais a personalidade humana do que tudo quanto inventara a ferocidade dos bárbaros, naquele dantesco rol de suplícios das nefandas ordenanças e ordenações. (Discurso pronunciado em 16 de abril de 1942, Revista da Faculdade de Direito, vol. XXXVIII, pág. 175 a 186).

\section{Discurso de agradecimento do Professor Cândido Motta Filho.}

Agradecendo a homenagem prestada ao Professor Cândido Nazianzeno Nogueira da Motta, o Prof. Cândido Motta Filho, em nome da família, pronunciou o seguinte discurso.

"A família de Cândido Motta agradece esta homenagem, com a qual a Faculdade de Direito de São Paulo. fiel a seus desígnios, não deixa que seu nome se perca nas enxurradas do nosso tempo.

"Particularmente grato estou por ouvir o que disse, o meu amigo e colega de ano, professor Noé Azevedo que substituíu Cândido Motta, com extraordinário brilho, na cátedra de Direito Penal.

"A solenidade de agora faz-me lembrar que a vida de Cândido Motta poderia dar motivo para um livro de sucesso, porque foi uma vida carregada de acontecimentos, na qual predominou, com um incurável e fecundo romantisno, uma densidade humana pouco comum. Réstif de 
La Bretonne, que foi um dos escritores mais fecundos de França, só se tornou famoso quando escreveu a vida simples de seu pai, de onde trouxe, para a curiosidade dos que gostam de ler, uma vida pacata e despretenciosa. de um camponio ligado mais aos vinhedos e à terra vermelha de sua propriedade do que a acontecimentos de monta. Para Restif as recordações sôbre seu pai eram sedutoras. porque de um homem que foi "commun et tous les jours..."

Não perdendo de vista o que Joaquim Nabuco escreveu ou o que Afonso Arinos de Melo Franco escreveu, vejo que só tenho fôlego para evocar, numa reunião de família acadêmica, o que havia de demasiadamente cordial em meu pai: - a ternura de sua vida afetiva, a docura de seus conselhos, a paciência de sua atenção, o exemplo de sua conduta de chefe de família, de homem público e de professor, a sua vontade de sobrepor às agruras e aos tormentos da vida o que a vida possui de melhor, nos ideais que elabora, nos princípios que compõe, tudo aquilo que resguarda a dignidade do homem, na dialética inevitável do bem e do mal.

Elle contava que dois acontecimentos foram sinaleiros de seu destino: - Nasceu em Pôrto Feliz, quando os voluntários de Araritaguába chegavam a Boiatuva, de volta da guerra do Paraguai. "Assim, dizia êle, nasci sôbre as promessas de paz e as esperanças republicanas." $O$ outro, foi o meu nascimento, o único filho sobrevivente que vinha à luz, quando êle se entregava, de corpo e alma, ao concurso da cadeira que conquistou. Seu filho seria conduzido pelo amor ao direito. Deveria acreditar no direito como êle acreditava e se tornaria também professor.

Foi, por isso, que procurou fazer sentir que eu devia viver nesta Casa como se fôsse a nossa casa. Lembro-me que, sem ter ainda alcançado os sete anos, subia, com êle, à cátedra e ficava, como animalzinho irriquieto, a ver a estudantada como um manancial de brinquedos. $\mathrm{E}$ mais tarde, me explicava que assim procedia para que eu fôsse 
compreendendo porque o direito existe e porque o direito se confunde com a vida.

Daí, o seu lema: "pela paz que constrói e pelo direito que a assegura."

Trabalhou muito, estudou muito e eu cresci em sua biblioteca como o gato Amilcar na biblioteca de Silvestre Bonnard. Machucou-se muitas vêzes, com as decepções que a realidade jogou em seu destino. Propagandista da República, viu a República cair ao peso de suas próprias contradições e viu o país, que o regime deveria engrandecer cada vez mais, padecer os tormentos das revoluções e o mundo as tormentas da guerra de todos contra todos.

Morreu contudo, com a alma intacta no culto de suas crenças,' com sua maneira de ver o homem como um milagre de Deus!

O professor viveu para esta Faculdade grande parte de sua vida. E foi da cátedra, diante de seus alunos, que deu graças por ter alcançado tudo o que alcançou!

$\mathrm{Eu}$ não poderia escrever sua vida, por que ela está demasiadamente em mim, nos meus filhos, nos meus netos e nos meus bisnetos. Só posso, e nem sei como posso. dar graças por ter tido um pai como tive e agradecer a esta Faculdade, ao seu eminente Diretor, e aos ilustres mestres, que tem assento na Congregação, êste instante de saudade. batido pelos doces perfumes de maio. E que, nêsse agradecimento, vejam também, nas minhas palavras, o transbordamento do que meu pai sempre pregou, sem jamais esmorecer: "a crença na paz que constrói e no direito que a assegura." 